\title{
Análise da viabilidade econômica e financeira para implantação de um aterro sanitário no município de Cabaceiras do Paraguaçu (BA)
}

O manejo dos resíduos sólidos urbanos constitui-se em um dos maiores desafios enfrentados pelas administrações públicas, pois, estes, quando não armazenados de forma adequada, podem causar danos tanto à saúde humana, quanto degradação ambiental. Visando promover melhorias para o Brasil em relação ao destino dado ao lixo urbano, o Governo Federal instituiu a Lei № 12.305 de 2010 acerca da Política Nacional de Resíduos Sólidos (PNRS), onde por meio desta, proíbe os municípios de destinarem os resíduos a vazadouros a céu aberto, os populares lixões, e, a obrigatoriedade para a implantação de um aterro sanitário. O município de Cabaceiras do Paraguaçu-BA, localizado no Recôncavo Baiano, por não possuir um aterro sanitário, transporta seus resíduos para o município de Muritiba-Ba. Assim, o objetivo principal dessa pesquisa é analisar a viabilidade econômica e financeira para implantação de um aterro sanitário no município supracitado. Quanto aos aspectos metodológicos o estudo, em relação ao delineamento, trata-se de um estudo de caso, uma vez que, analisa uma situação concreta, numa localidade específica. A natureza da pesquisa é descritiva, pois tem a finalidade de apenas registrar e analisar os fenômenos técnicos, sem, contudo, entrar nos méritos dos resultados encontrados. A abordagem, por sua vez, é de natureza qualitativa, pois esta se insere no contexto social do município. Para alcance do proposto, foram utilizadas ferramentas de engenharia econômica, a exemplo de Valor Presente Líquido (VPL), Taxa Interna de Retorno (TIR) e o prazo de recuperação do investimento (PAYBACK). A partir dos resultados obtidos compreende-se que para a implantação de um aterro sanitário de pequeno porte no município é necessária uma área de $10.000 \mathrm{~km} 2$ com capacidade para receber até 100 toneladas de lixo por dia. Quanto à análise econômica e financeira do projeto foram realizadas projeções para 10 anos (cenários para administração pública) e 15 anos (cenários para concessão privada). A análise de viabilidade para primeiro cenário provável (administração pública) e para o terceiro cenário provável (concessão privada), não foi satisfatória, uma vez que o VPL apresentou valores negativos. Já no segundo cenário (administração pública), e no quarto cenário (concessão privada), otimistas, o projeto foi viável, devido à manipulação de algumas variáveis.

Palavras-chave: Análise de Viabilidade; Aterro Sanitário; Lei 12.305/2010

\section{Analysis of economic and financial viability for deployment of a landfill in the Cabaceiras Paraguaçu municipality (BA)}

\begin{abstract}
The management of urban solid waste is in one of the biggest challenges faced by government, for these, when not stored properly, can cause damage both to human health, as environmental degradation. To promote improvements to Brazil in relation to the destination of the urban waste, the Federal Government introduced Law No. 12,305 of 2010 on the National Solid Waste Policy (PNRS) where hereby prohibits municipalities of destined waste to dumps the open, the popular garbage dumps, and the requirement for the implementation of a landfill. The Cabaceiras municipality of Paraguaçu, Bahia, located in the Reconcavo Baiano, for not having a landfill, transports its waste to the city of Muritiba-Ba. Thus, the main objective of this research is to analyze the economic and financial feasibility for the implementation of a landfill in the above municipality. As for the methodological aspects the study in relation to the design, it is a case study, as it examines a concrete situation in a specific location. The nature of research is descriptive, it is intended to only record and analyze the technical phenomena without, however, go into the merits of the findings. The approach, in turn, is qualitative, because this fits into the social context of the city. To reach the proposed economic engineering tools were used, like Net Present Value (NPV), Internal Rate of Return (IRR) and the period of investment recovery (PAYBACK). From the obtained results it is understood that for the implementation of a landfill in the small municipality an area of $10,000 \mathrm{~km} 2$ with capacity is required to receive up to 100 tons of garbage a day. As for economic and financial analysis of the project forecasts were made for 10 years (scenarios for public administration) and 15 years (scenarios for private concession). Viability analysis for first probable scenario (public administration) and the third probable scenario (private grant) were unsatisfactory, since the NPV was negative. In the second scenario (public administration), and the fourth scenario (private concession), optimistic, the project was feasible, due to the manipulation of certain variables.
\end{abstract}

Keywords: MASP; PDCA; Quality Tools.

\section{Topic: Teoria Geral da Admistração}

Reviewed anonymously in the process of blind peer.

\section{Luís Oscar Silva Martins}

Universidade Estadual de Feira de Santana, Brasil

http://lattes.cnpq.br/3412627894520906

luisoscar2007@hotmail.com

Quézia Pinto da Silva

Faculdade Maria Milza, Brasil

http://lattes.cnpq.br/7001839837261708

queziapinto@hotmail.com
Received: 08/02/2016

Approved: 15/07/2016
Referencing this:

MARTINS, L. O. S.; SILVA, Q. P.. Análise da viabilidade econômica e financeira para implantação de um aterro sanitário no município de Cabaceiras do Paraguaçu (BA). Revista Brasileira de Administração Científica, v.7, n.2, p.68-85, 2016. DOI: http://doi.org/10.6008/SPC2179-684X.2016.002.0005 


\section{INTRODUÇÃO}

O aumento da intensidade da atividade humana nas últimas décadas, bem como, o crescimento desordenado da população em núcleos urbanos sem planejamento acelerou a produção excessiva de resíduos sólidos urbanos, causando uma série de problemas para a sociedade, em especial à gestão pública. Esse crescimento contínuo da escala econômica sobre o meio ambiente agravou uma questão específica no processo de sustentabilidade relacionada às ações de manejo de resíduos e sua correta disposição final.

As consequências ambientais decorrentes do inadequado tratamento dado aos resíduos sólidos urbanos são sentidas diretamente no ar, nas águas (subterrâneas e superficiais) e no solo, pois o lixo acumulado gera um líquido chamado chorume ${ }^{1}$, que contém componentes tóxicos e atingem diretamente os lençóis freáticos.

Sendo assim, o Governo Federal instituiu a Lei № 12.305 de 2010 acerca da Política Nacional de Resíduos Sólidos (PNRS), onde por meio desse marco legal proíbe os municípios de destinarem os resíduos sólidos em vazadouros a céu aberto, e, estabelece a obrigatoriedade para a implantação de aterros sanitários integrando ainda a coleta seletiva. Independentemente do tamanho do município ou de sua localização, todos devem possuir um aterro, sendo que a total responsabilidade sobre os serviços de manejo dos resíduos fica a cargo do município.

O município de Cabaceiras do Paraguaçu (BA) por não possuir um aterro sanitário, todo resíduo produzido é transportado para o município vizinho de Muritiba (BA), que possui o equipamento. Assim, o presente trabalho fez uma análise econômica e financeira acerca da viabilidade para a construção de um aterro sanitário no município, ou seja, foi analisado se é mais rentável possuir um aterro ou transportar esses resíduos sólidos para outra localidade.

Nesse contexto, o objetivo geral dessa pesquisa é analisar a viabilidade econômica e financeira para implantação de um aterro sanitário no município de Cabaceiras do Paraguaçu. No intuito de alcançar esse objetivo foram instituídos os seguintes objetivos específicos: (a) Diagnosticar o potencial de resíduos sólidos gerados no município de Cabaceiras do Paraguaçu; (b) Estimar o capital inicial necessário para implantação de um aterro sanitário no município em epígrafe, e, as entradas e saídas de caixa necessárias para elaboração de fluxo de caixa livre para implantação do projeto; (c) Aplicar a metodologia de análise de viabilidade econômica e financeira no empreendimento.

O artigo consta de mais cinco seções além desta introdução. O próximo ponto a ser abordado é o referencial teórico, que mostrará os dados referentes ao Brasil, Região Nordeste e ao Estado da Bahia quanto à destinação dos resíduos sólidos e informações sobre o município de Cabaceiras do Paraguaçu além dos aspectos relacionados à temática debatida nesta pesquisa à luz da Lei 12.305/2010. No terceiro capítulo foram abordados os aspectos metodológicos utilizados para estimativa do investimento inicial do projeto, como também a apresentação das ferramentas de engenharia econômica de análise para alcance dos

\footnotetext{
${ }^{1} \mathrm{O}$ chorume é um resíduo líquido de elevada carga orgânica e forte coloração, produzido pela decomposição química e microbiológica dos resíduos sólidos depositados em um aterro (MORAIS et al., 2006).
} 
resultados, tais como: Valor Presente Líquido (VPL), Taxa Interna de Retorno (TIR), e o Prazo de recuperação do investimento (Payback). O capitulo quatro foi dedicado à análise e discussões da temática envolvida e finalmente na seção cinco foram apresentadas as conclusões e recomendações da pesquisa.

\section{REFERENCIAL TEÓRICO}

\section{A Problemática do Lixo no Contexto Nacional}

Um dos principais equipamentos que podem auxiliar no manejo do RSU é o aterro sanitário, que de acordo com Vilhena et al. (2010) "constituiu-se no método mais adequado para disposição de todo tipo de resíduo, incluindo os de serviços de saúde". Deste modo faz-se necessário obter um destino adequado para os resíduos gerados, para que não haja danos a população ou ao meio ambiente (SOUSA et al., 2010).

O Plano Nacional de Resíduos Sólidos (PNRS, 2012) considera como as principais modalidades de destinação final: aterro sanitário, aterro controlado e vazadouro a céu aberto (lixão). De acordo com o Programa das Nações Unidas para o Desenvolvimento (PNUD, 2010) lixões ou vazadouros a céu aberto são locais onde o lixo é lançado sobre o terreno sem qualquer cuidado ou técnica especial.

Para o Instituto Brasileiro de Geografia e Estatística (IBGE), outro método para a disposição final dos resíduos é o aterro controlado, local utilizado para despejo do lixo coletado, em bruto, com cuidado de diariamente após a jornada de trabalho cobrir os resíduos com uma camada de terra, minimizando os impactos ambientais, porém a Associação Brasileira de Empresas de Limpeza Pública e Resíduos (ABRELPE, 2013) afirma que do ponto de vista ambiental, pouco se diferenciam dos lixões, pois não possuem o conjunto de sistemas necessários para a proteção do meio ambiente e da saúde pública.

O aterro sanitário é um processo utilizado para a disposição de resíduos sólidos no solo, fundamentado em critérios de engenharia e normas operacionais especificas, permite um confinamento seguro em termos de controle de poluição ambiental e proteção à saúde pública (VILHENA et al., 2010).

Os resíduos sólidos são resultado das ações humanas, provenientes de residências, indústrias, hospitais e construções que são gerados após a utilização dos bens. "Os resíduos sólidos definidos como resto das atividades humanas, são considerados pelos geradores como inúteis, indesejáveis ou descartáveis" (SOUSA et al., 2010). Segundo a Associação Brasileira de Normas Técnicas (ABNT) através da NBR no 10004, de 2004, que trata da classificação dos resíduos sólidos, define os mesmos como:

Aqueles resíduos nos estados sólido e semi-sólido, que resultam de atividades da comunidade de origem industrial, doméstica, hospitalar, comercial, agrícola, de serviços e de varrição. Ficam incluídos nesta definição os lodos provenientes de sistemas de tratamento de água, aqueles gerados em equipamentos e instalações de controle de poluição, bem como determinados líquidos cujas particularidades tornem inviável o seu lançamento na rede pública de esgotos ou corpos de água, ou exijam para isso soluções técnicas e economicamente inviáveis em face a melhor tecnologia disponível (ABNT, 2004).

Observa-se que a ABNT define como resíduos sólidos, todos os objetos ou bens que são descartados resultantes da atividade humana em sociedade, abrangendo várias origens, como residencial, comercial, hospitalar, industriais, da limpeza pública (varrição e poda), da construção civil e os agrícolas. Os serviços de manejo dos resíduos sólidos compreendem a coleta, a limpeza pública, bem como a destinação final desses 
resíduos, definindo que é de responsabilidade do poder público local o gerenciamento dos resíduos sólidos produzidos em suas respectivas áreas (PNSB, 2008).

A intensificação das atividades humanas nas últimas décadas gerou um acelerado aumento na produção de resíduos, tornando-se um grave problema para as administrações públicas. $O$ aumento desordenado da população e o crescimento sem planejamento de grandes núcleos urbanos dificultam as ações e o manejo dos resíduos, os quais, muitas vezes são depositados em locais não preparados para recebêlos, como lixões, e podem provocar graves problemas socioambientais (PNUD, 2010).

Os resíduos depositados em um lixão causam poluição ao solo, ao ar e as águas, atraem vetores de doenças, não os restringem de serem levados pela ação do vento e por animais, não controla o risco de deslizamentos, fogo, explosões e por fim ajudam a manter um grave problema social, caracterizado pelo uso de mão-de-obra que trabalha num regime de quase servidão em condições subumanas, ou seja, os catadores que sobrevivem da coleta do lixo (PNUD, 2010).

A Lei 12.305, de 2 de agosto de 2010, instituiu a Política Nacional de Resíduos Sólidos (PNRS), dispondo sobre as diretrizes relativas à gestão integrada, ao gerenciamento de resíduos sólidos, incluídos os perigosos, e, as responsabilidades dos geradores do lixo e do poder público.

O marco legal confirma a obrigatoriedade da disposição final dos resíduos sólidos em aterros sanitários, conforme Artigo 3ㅇ, Inciso VIII, que afirma: "disposição final ambientalmente adequada: distribuição ordenada de rejeitos em aterros, observando normas operacionais específicas de modo a evitar danos ou riscos à saúde pública e à segurança e a minimizar os impactos ambientais adversos".

A responsabilidade pelo lixo passa a ser compartilhada, com obrigações que envolvem os cidadãos, as empresas (de direito público ou privado), as Prefeituras, os Governos Estaduais e o Governo Federal. 0 Sistema Nacional de Vigilância Sanitária (SNVS), definido pela Lei no 9.782, de 26 de janeiro de 1999, é um instrumento que o Sistema único de Saúde (SUS) dispõe para realizar seu objetivo de prevenção e promoção da saúde. O Sistema Nacional do Meio Ambiente (SISNAMA) foi instituído pela Lei 6.938, de 31 de agosto de 1981, e, é responsável pela proteção e melhoria da qualidade ambiental, ambos são constituídos pelos órgãos e entidades da União, dos Estados, do Distrito Federal e dos municípios.

Art. 10. Incumbe ao Distrito Federal e aos Municípios a gestão integrada dos resíduos sólidos gerados nos respectivos territórios, sem prejuízo das competências de controle e fiscalização dos órgãos federais e estaduais do Sisnama, do SNVS e do Suasa, bem como da responsabilidade do gerador pelo gerenciamento de resíduos, consoante o estabelecido nesta Lei.

De acordo com a Lei, todas as administrações públicas municipais, indistintamente do seu porte e localização, devem construir aterros sanitários e encerrarem as atividades dos lixões e aterros controlados. Art. 17ำ, Inciso $V$, "metas para a eliminação e recuperação de lixões, associadas à inclusão social e à emancipação econômica de catadores de materiais reutilizáveis e recicláveis".

As administrações municipais devem desenvolver um Plano de Gestão Integrada de Resíduos. Caso descumpram essa obrigação ficam proibidas de receber recursos de fontes Federais, destinadas ao gerenciamento de resíduos. 
Art. 18. A elaboração de plano municipal de gestão integrada de resíduos sólidos, nos termos previstos por esta Lei, é condição para o Distrito Federal e os Municípios terem acesso a recursos da União, ou por ela controlados, destinados a empreendimentos e serviços relacionados à limpeza urbana e ao manejo de resíduos sólidos, ou para serem beneficiados por incentivos ou financiamentos de entidades federais de crédito ou fomento para tal finalidade.

Assim, segundo Art. 47, "São proibidas as seguintes formas de destinação ou disposição final de resíduos sólidos ou rejeitos".

I - lançamento em praias, no mar ou em quaisquer corpos hídricos;

II - lançamento in natura a céu aberto, excetuados os resíduos de mineração;

III - queima a céu aberto ou em recipientes, instalações e equipamentos não licenciados para essa finalidade.

No Art. 54, "a disposição final ambientalmente adequada dos rejeitos, observado o disposto no parágrafo $\S 1^{\circ}$ do art. 9oㅡㄹ deverá ser implantada em até 4 (quatro) anos após a data de publicação desta Lei". Contudo muitas administrações públicas não conseguiram cumprir a Lei no prazo imposto que venceu em agosto de 2014.

\section{Geração e Destinação Final dos Resíduos Sólidos Urbanos}

No Brasil, a geração total de RSU, segundo a ABRELPE (2013), foi de 76.387 .200 toneladas (t) no ano de 2013 , representando um aumento de 4,1\%, em relação ao ano de 2012 , índice que é superior à taxa de crescimento populacional no país no período, que foi de 3,7\%. O dado de geração diário em 2013 foi de 1,041 kg comparado com o ano de 2012 que foi de 1,037 evidenciando um aumento de 0,39\%. "Alterando-se a quantidade e qualidade dos bens consumidos, altera-se também o padrão de geração de resíduos pela população em geral e por cada domicílio em particular" (SILVA et al., 2012) (Figura 1).

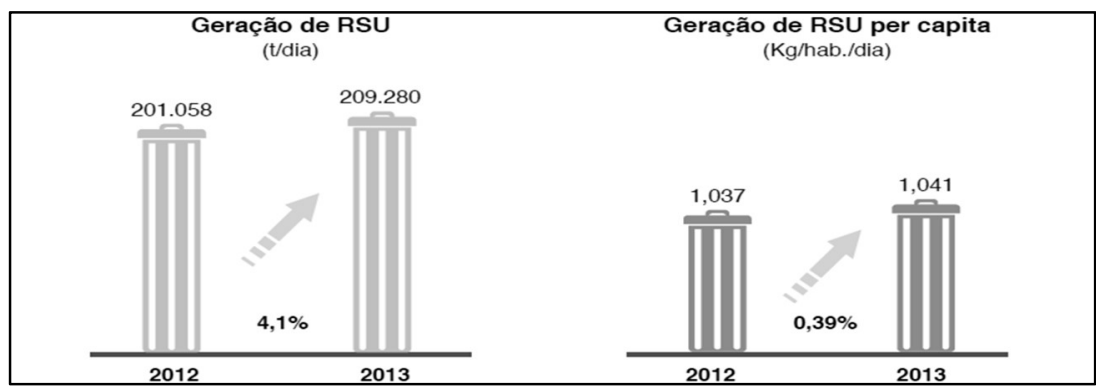

Figura 1: Geração de RSU no Brasil. Fonte: ABRELPE (2013)².

A Figura 2 demonstra que houve um aumento de 4,4\% na quantidade de RSU coletados em 2013 comparados a 2012. A comparação deste índice com o crescimento da geração de RSU mostra uma discreta evolução na cobertura dos serviços de coleta, chegando a 90,4\%. Foram coletados 69.064 .935 t de resíduos, e deixou de recolher 7.322.265 t de resíduos em 2013, que por consequência tiveram destino impróprio. 


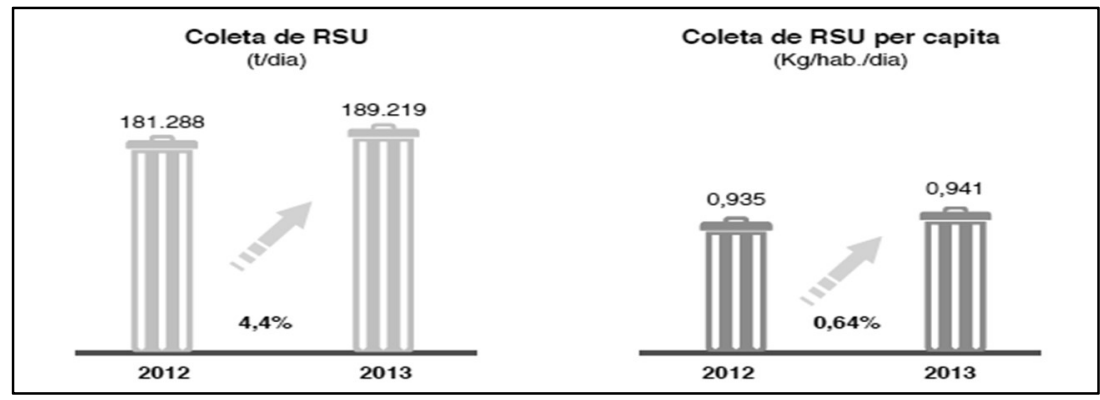

Figura 2: Coleta de RSU no Brasil. Fonte: ABRELPE (2013)

De acordo com os dados referentes à Figura 3 a destinação final dos RSU no Brasil no ano de 2013, $58,3 \%$ (110.232 t) seguiu para aterros sanitários e enquanto que, para os lixões, foram de 17,4\% (32.946 t). É perceptível uma evolução gradativa, a partir da incorporação da perspectiva da sustentabilidade no gerenciamento desses resíduos gerados nos centros urbanos.

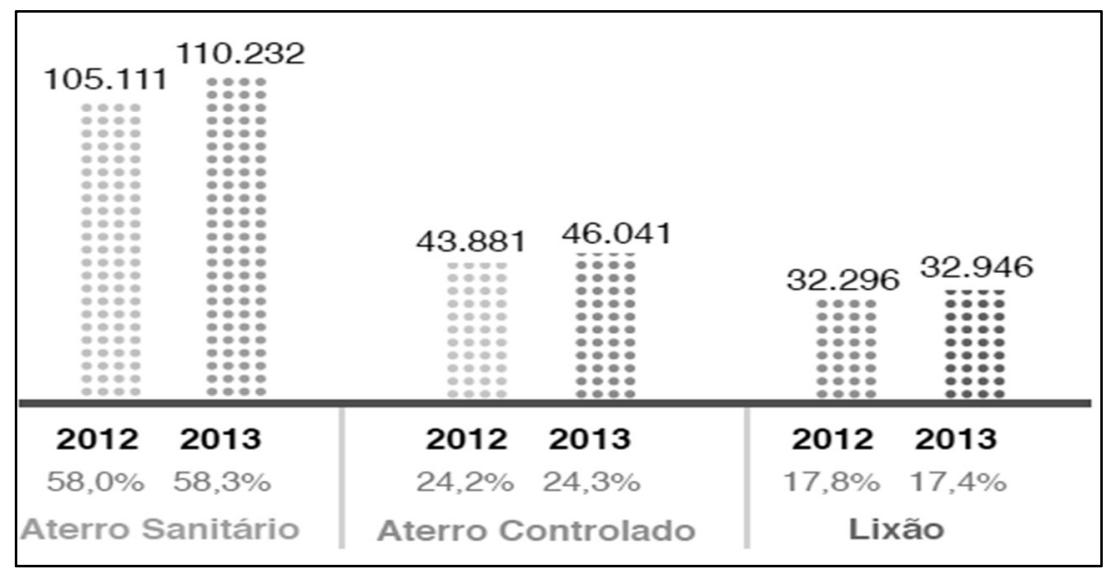

Figura 3: Destinação final de RSU (t/dia) no Brasil. Fonte: ABRELPE (2013).

Os 1.794 municípios dos nove Estados da região Nordeste geraram, em 2013, a quantidade de 53.465 toneladas/dia de RSU, das quais $78,2 \%$ foram coletadas. A região Nordeste é ainda a que possui umas das taxas mais altas em relação à quantidade de lixões a céu aberto, comparadas a outras regiões brasileiras. Conforme a Figura 4 os dados relativos à destinação adequada de RSU não apresentou evolução de 2012 para 2013 na região. Dos resíduos coletados no território, 64,8\%, que correspondem a 27.116 toneladas diárias, ainda são destinados para lixões e aterros controlados (ABRELPE, 2013).

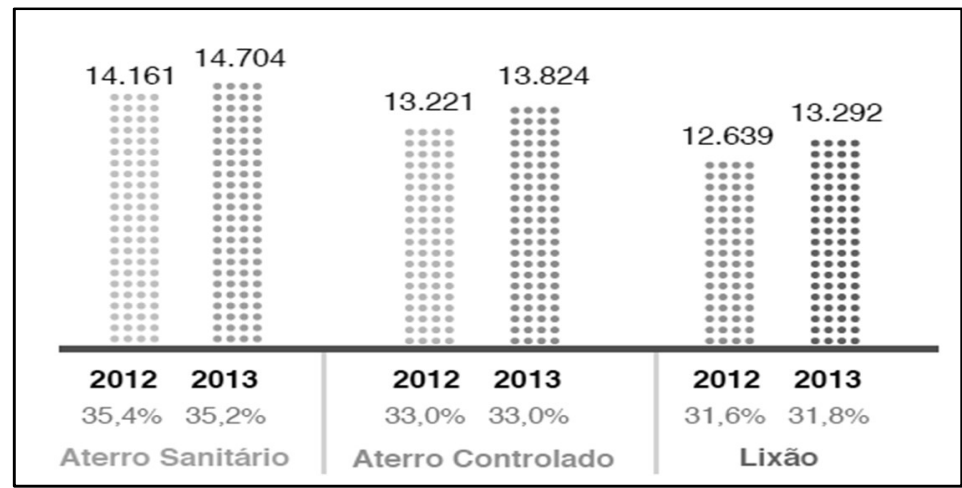

Figura 4: Destinação final de RSU na Região Nordeste (t/dia). Fonte: ABRELPE (2013).

${ }^{3}$ Os índices per capita referentes a 2013 e 2012 foram calculados com base na população total dos municipios. 
O Estado da Bahia possui 417 municípios com Área $\left(\mathrm{km}^{2}\right)$ 564.733,081 e uma população estimada para 2014 de 15.126.371 habitantes (IBGE, 2010). De acordo com a Tabela 2, foram geradas, em 2013, 14.235 t por dia totalizando 5.195.775 t por ano de resíduos sólidos urbanos, sendo que foram coletados no Estado 11.506 t/dia totalizando 4.199.690 toneladas no ano. Por meio dessa análise percebe-se que deixaram de ser coletadas 996.085 t, denotando que esses RSU foram lançados em locais impróprios como, os lixões.

Tabela 1: Coleta e Geração de RSU no Estado da Bahia.

\begin{tabular}{l|l|l|l|l|l|l|l}
\hline \multirow{2}{*}{ População Total } & \multicolumn{3}{c|}{ RSU Coletado } & \multicolumn{2}{c}{ RSU Gerado (t/dia) } \\
\cline { 2 - 8 } & \multicolumn{3}{c}{ (Kg/hab./dia) } & \multicolumn{2}{c}{ (t/dia) } \\
\hline 2012 & 2013 & 2012 & 2013 & 2012 & 2013 & 2012 & 2013 \\
\hline 14.175 .341 & 15.044 .137 & 0,759 & 0,765 & 10.754 & 11.506 & 13.620 & 14.235 \\
\hline
\end{tabular}

Fonte: Adaptado ABRELPE (2013)

De acordo com a Secretaria de Desenvolvimento Urbano (SDU) e o Ministério Do Meio Ambiente (MMA, 2012) os dados quanto à destinação final dos resíduos sólidos, exposto pela Tabela 2 os vazadouros a céu aberto (lixão), são utilizados na maioria dos municípios do Estado, correspondendo a 86,51\% (359 municípios), 8,43\% manejaram os resíduos para aterros simplificados ou controlados (35 municípios) e 5,28\% (22 municípios) destinam para aterro convencional. Portanto, com a amostra desses resultados, observa-se que ainda há muito a ser feito no estado em relação à construção de políticas públicas de gerenciamento de RSU, que pode ser exercido através de programas do governo voltados para o meio ambiente nas cidades baianas.

Tabela 2: Quantidade de Unidades de Destinação Final na Bahia.

\begin{tabular}{c|c|c}
\hline \multirow{2}{*}{ Tipo de destinação final } & \multicolumn{2}{|c}{ Quantidade de unidades } \\
\cline { 2 - 3 } & $\mathbf{N}^{\circ}$ & 0,24 \\
\hline Unidades de Compostagem e Reciclagem & 1 & 4,82 \\
\hline Aterro Sanitário Convencional & 20 & 8,43 \\
\hline Aterro Sanitário Simplificado & 35 & 86,51 \\
\hline Vazadouro a Céu Aberto (lixão) & 359 & $\mathbf{1 0 0 , 0}$ \\
\hline Total & $\mathbf{4 1 5}$ & \\
\hline
\end{tabular}

Fonte: Plano de Regionalização da Gestão Integrada de Resíduos Sólidos para o Estado da Bahia (2012).

O município de Cabaceiras do Paraguaçu, situado no Recôncavo Baiano, antigo distrito de Muritiba, emancipado em 13 de junho de 1889, a 88 km de Salvador, com uma população estimada para 2014 de 18.850 habitantes e possui uma área de unidade territorial de $226,015 \mathrm{~km}^{2}$ (IBGE, 2010).

Quanto à produção de resíduos observa-se na Tabela 3 que o total estimado em 2010 foi de aproximadamente $2,786 \mathrm{~kg} / \mathrm{dia}$, a população urbana projetada para 2015 é de 5.124 habitantes, responsável pela produção diária total de resíduos de aproximadamente $3.152 \mathrm{~kg}$, e os resíduos estimados para ano de 2033, totaliza aproximadamente 4,917 kg/dia (SDU; MMA, 2012).

Tabela 3: Produção total de RSU para o município de Cabaceiras do Paraguaçu.

\begin{tabular}{l|c|c|c|c|c|c}
\hline \multicolumn{1}{c}{ Município } & $\begin{array}{c}\text { População } \\
2010\end{array}$ & $\begin{array}{c}\text { Produção p/ } \\
2010(\mathrm{~kg} / \mathrm{dia})\end{array}$ & $\begin{array}{c}\text { População Proj. } \\
2015\end{array}$ & $\begin{array}{c}\text { Produção p/ } \\
2015(\mathrm{~kg} / \mathrm{dia})\end{array}$ & $\begin{array}{c}\text { População Proj. } \\
2033\end{array}$ & $\begin{array}{c}\text { Proj. Produção } \\
\mathrm{p} / 2033(\mathrm{~kg} / \mathrm{dia})\end{array}$ \\
\hline $\begin{array}{l}\text { Cabaceiras do } \\
\text { Paraguaçu }\end{array}$ & 4.644 & 2.786 & 5.124 & 3.152 & 7.307 & 4.917 \\
\hline
\end{tabular}

Fonte: Adaptado, Plano de Regionalização da Gestão Integrada de Resíduos Sólidos para o Estado da Bahia (2012).

${ }^{4}$ Os índices per capita referentes a 2013 e 2012 foram calculados com base na população total dos municípios. 
Em 2005, foi implantado pelo Governo do Estado por meio da Companhia de Desenvolvimento Urbano do Estado da Bahia (CONDER), um aterro simplificado no município de Cabaceiras, com vida útil de 10 anos, porém a proposição é o encerramento do mesmo já que o município está utilizando o aterro sanitário convencional compartilhado de Muritiba que fica a 27 km de Cabaceiras (SDU; MMA, 2012).

\section{Ferramentas de Análise de Viabilidade e Custo de Capital}

Antes de ser implantado o empreendimento é necessário um estudo de viabilidade técnica, econômica e financeira para que através deste seja analisado se o projeto é ou não viável. A análise irá demonstrar através de projeções, o investimento inicial, e, o potencial retorno. E para isso serão utilizadas as ferramentas de engenharia econômica.

De acordo com Hoji (2007) a engenharia econômica "tem a finalidade de possibilitar a escolha da melhor alternativa de investimento, utilizando métodos de análise específicos, com a consequente otimização dos recursos". Desta forma, um investimento envolve sacrifício de grande volume de recursos humanos, intelectuais, materiais e financeiro, e seu retorno dever ser compatível com o nível de risco assumido, por isso as decisões devem ser tomadas com base em informações cuidadosamente analisadas.

No projeto são analisados os aspectos técnicos que examinam a localização, as necessidades técnicas para o empreendedorismo, a mão de obra, as taxas e tributos, bem como os incentivos eventualmente existentes, concluindo-se pelos possíveis custos de investimentos e custos operacionais. Os aspectos econômicos e contábeis apresentam os balanços previstos, baseados nos possíveis resultados operacionais, são analisados fatores representativos como liquidez, capital de giro, rentabilidade, ativos e passivos, além de valores patrimoniais da empresa. $E$ os aspectos financeiros são examinados por meio das projeções do fluxo de caixa para o empreendimento dentro de um prazo de interesse, e, são examinadas as diversas taxas de juros que possam atuar sobre o fluxo. (HIRSCHFELD, 2012).

O fluxo de caixa referente a um empreendimento deve conter as entradas e as saídas de capital que vão atuar ao longo do prazo analisado. As saídas dizem respeito aos gastos com investimentos em bens como terrenos, equipamentos, móveis e utensílios; custos mensais com aluguéis, materiais, mão de obra, impostos, taxas, consumos de água e luz, etc.; financiamentos e IPTU. Quanto às entradas dizem respeito aos recebimentos das vendas de bens, aplicações financeiras e recebimentos resultantes do faturamento. (HIRSCHFELD, 2012).

A projeção do fluxo de caixa se configura em: investimento inicial que representa o ano 0 , onde entende-se como todo capital necessário para colocar o projeto em funcionamento e os anos seguintes representam o ingresso ou a saída de caixa no período; o faturamento é resultante do somatório dos ganhos obtidos; custos fixos compreendem a aquisição de terreno, máquinas equipamentos, veículos, ferramentas, moveis e utensílios etc., e os variáveis são referentes as despesas com água, luz etc.; a depreciação dos bens corresponde a diminuição do valor desses, resultantes do desgaste pelo uso, embora represente um custo de produção não se materializa em desembolso. 
O LAJIR é resultante do lucro antes dos juros e os impostos sobre a renda; as despesas financeiras dizem respeito aos os juros que a empresa deve pagar aos seus credores; o imposto de renda corresponde ao valor anual descontado, sendo devido tanto pelas pessoas jurídicas quanto físicas; o fluxo líquido é resultante da receita deduzida dos custos, depreciação, LAJIR, juros e o Imposto de Renda (IR); a variação no capital de giro corresponde à variação do montante de recursos que são aplicados no giro das operações; a amortização diz respeito ao processo de pagamentos periódicos de uma dívida no qual cada prestação os juros é embutido; e por fim o fluxo de caixa final que corresponde ao saldo de todas as operações de caixa.

Ao se fazer uma análise de um empreendimento gera a necessidade de utilizar a engenharia econômica como um procedimento para a avaliação dos investimentos. "A engenharia econômica utiliza métodos de análise específicos que possibilitam a escolha da melhor alternativa de investimento, com a consequente otimização dos recursos" (HOJI, 2004).

Esses métodos que irão dar suporte a essa análise de viabilidade são os seguintes: Valor Presente Líquido (VPL), Taxa interna de Retorno (TIR), Período de Recuperação do Investimento (Payback) e o Índice de Lucratividade (IL), que serão apresentadas a seguir.

De acordo com Gitman (2004), o Valor Presente Líquido (VPL) considera o valor do dinheiro no tempo, a partir do fluxo de caixa é estipulada uma taxa, que é frequentemente chamada de taxa de desconto, retorno exigido, custo de capital ou custo de oportunidade, que é o retorno mínimo que deve ser alcançado no projeto. Portanto, será comparado o capital inicial investido com o que for gerado pelo projeto para então identificar se a rentabilidade foi maior que o investimento. Então, o VPL é igual ao somatório do fluxo de caixa de cada período $\left(F C_{t}\right)$, dividido por 1 mais a taxa de desconto escolhida $(k)$ elevada ao seu respectivo período $(t)$ subtraindo-se o investimento inicial $\left(F C_{0}\right)$.

$$
V P L=\sum_{t=1}^{n} \frac{F C_{t}}{(1+k)^{t}}-F C_{0}
$$

Figura 5: Fórmula do Valor Presente Líquido (VPL). Fonte: Gitman (2004).

Os critérios considerados para a tomada de decisão do projeto, de aceitação ou rejeição são as seguintes: Se o VPL for maior que $\$ 0$, o projeto deverá ser aceito. Mas se o VPL for menor que $\$ 0$, o projeto deverá ser rejeitado. E se o VPL for igual a \$ 0 o retorno mínimo exigido é indiferente em relação ao projeto. (GITMAN, 2004).

Para Ross (2008) a Taxa Interna de Retorno (TIR) de um investimento, é a taxa exigida de retorno que iguala o VPL a zero quando utilizada como taxa de desconto. Com base na TIR o investimento é aceito quando esse for maior do que o retorno exigido. A TIR não é a taxa de retorno do projeto e sim uma taxa parâmetro. Portanto, a TIR é igual ao o somatório do fluxo de caixa de cada período $\left(F C_{t}\right)$, dividido por 1 mais a taxa interna de retorno $(T I R)$ elevada ao seu respectivo período $(t)$ subtraindo-se o investimento inicial $\left(F C_{0}\right)$.

$$
\$ 0=\sum_{t=1}^{n} \frac{F C_{t}}{(1+T I R)^{t}}-F C_{0}
$$

Figura 6: Fórmula da Taxa Interna de Retorno (TIR). Fonte: Gitman (2004). 
O VPL e a TIR podem fornecer resultados diferentes, mas ambos os métodos "devem chegar à mesma conclusão quanto à aceitação ou à rejeição de projetos" (GITMAN, 2004).

A quantidade de anos necessários para a recuperação de um investimento inicial é conhecida como Período de Recuperação do Investimento (Payback). Se o período encontrado representar um tempo aceitável, então o projeto será selecionado (GROPPELLI et al., 2006). Deste modo o Payback indica o momento em que o projeto gerou a mesma quantidade de Caixa que gastou no início do projeto, assim, o investidor saberá quanto tempo terá que esperar para obter o retorno do capital investido.

\section{METODOLOGIA}

A pesquisa se caracteriza como descritiva, pois trata-se do estudo, análise, registro e interpretação dos fatos, ou seja, ela descreve os acontecimentos de uma determinada realidade sem que haja a interferência do pesquisador. O objetivo primordial é a descrição das características de determinada população ou fenômeno, sendo que, utiliza de técnicas padronizadas de coleta de dados, como a observação sistemática e o a aplicação de questionários. (GIL, 2002).

Quanto ao delineamento da pesquisa o método adotado foi como estudo de caso, que de acordo com Yin (2001), é uma investigação empírica que averigua um fenômeno atual dentro do contexto da vida real, então utiliza-se o método de estudo quando o pesquisador deseja lidar com condições contextuais crendo que elas podem estar relacionadas ao fenômeno de estudado.

Ainda segundo o autor, o estudo de caso como estratégia de pesquisa compreende um método que abrange o todo permitindo amplo detalhamento e conhecimento, sendo assim, através de um planejamento é incorporado abordagens específicas à coleta de dados e à análise dos mesmos. É estudo de caso, pois a pesquisa se trata de uma situação específica.

A abordagem, por sua vez, é de natureza qualitativa, pois está se insere no contexto social do município de Cabaceiras do Paraguaçu, visando através desta, beneficiar a comunidade e fornecer ferramentas para que o município se enquadre a Lei 12.305 instituída pelo Governo Federal acerca da obrigatoriedade para a implantação de um aterro sanitário. De acordo com Demo (2000), a pesquisa qualitativa faz jus à complexidade da realidade, são consideradas pelo autor metodologias qualitativas: pesquisa participante, pesquisa-ação, história oral, hermenêutica, levantamentos feitos com questionários abertos ou diretamente gravados, etc., no qual abrigam horizontes bastante heterogêneos.

Os dados coletados para a realização do projeto, no que tange, especialmente, às entradas de caixa do fluxo, foram perpetrados por meio de entrevistas com o Diretor de Agricultura, Secretário de Transportes e o Secretário de Finanças do município de Cabaceiras do Paraguaçu, onde foram levantados os custos referentes ao recolhimento e transporte desses resíduos para o município de Muritiba.

As informações referentes aos custos do projeto foram alcançadas por meio de visita técnica e entrevista semiestruturada elaborada com o gestor da Empresa BATTRE, localizada no município de Lauro de Freitas - BA, e responsável pela administração dos aterros sanitários dos municípios de Simões Filho, 
Salvador, bem como do município supracitado. Neste buscou-se informações estratégicas como as despesas incorridas, custos diretos e indiretos de produção.

Com base nessas informações foi montado o fluxo de caixa por um período de dez anos no que se refere à exploração do setor público, e quinze anos para a concessão privada apresentando para ambos um cenário provável e otimista, esse período estipulado é dado em relação ao tempo de vida útil do aterro sanitário. No fluxo de caixa foi detalhado: o investimento inicial, os gastos fixos e variáveis para a implantação do projeto.

De acordo com o já relatado no referencial teórico as ferramentas que foram utilizadas são o VPL, que calcula os fluxos de caixas deduzidos a valor presente, descontada a taxa de custo de capital do investidor, subtraindo-se esse valor do investimento inicial, gerando um resultado positivo no caso de viabilidade, nulo, no caso de indiferença e negativo no caso de inviabilidade; a TIR se caracteriza como a taxa que torna nulo o VPL atuando como um parâmetro comparativo em relação a taxa de custo do capital, ou seja, se a TIR for maior que a taxa de custo do capital, aceita-se o projeto, caso contrário, rejeita-se; finalmente o PAYBACK descontado, dimensiona o prazo de retorno do capital investido.

\section{RESULTADOS E DISCUSSÃO}

\section{Análise Econômica e Financeira}

A análise de viabilidade econômica e financeira se dá através de uma comparação entre a situação atual de disposição dos resíduos, ou seja, quanto é gasto atualmente pelo município para descartar o lixo no aterro do município de Muritiba, e os investimentos iniciais, os custos fixos e variáveis necessários para a implantação de um aterro próprio.

Se o VPL for positivo indica que o capital investido será recuperado, remunerado na taxa de juros (TIR) que mede o custo de capital do projeto, e o retorno financeiro (Payback), neste é medido quanto tempo é preciso para cobrir os custos de investimento.

Foram analisados os fluxos de caixa ao longo de dez anos para um cenário provável e otimista com o objetivo da administração pública, e quinze anos para um cenário provável e otimista no intuito da concessão privada. Nestes, estão envolvidos os custos fixos e variáveis, bem como os investimentos iniciais e os impostos recolhidos no aterro.

A receita gerada para empreendimento é dada através da quantidade de lixo multiplicado pelo preço da tonelada. Para os cenários prováveis foi utilizado o preço atual pago pela prefeitura de Cabaceiras do Paraguaçu (BA) no aterro de Muritiba (BA), esse valor é de $\mathrm{R} \$ 58,92$ para o primeiro ano do projeto, com acréscimo de 3\% ao ano. Esse acréscimo de 3\% é de praxe em trabalhos desse tipo. Ministério do Meio Ambiente (MMA, 2010). Já para os cenários otimistas foi utilizado como parâmetro para estipular o preço o estudo da Fundação Getúlio Vargas, FGV Projetos (2007), onde o preço cobrado pela tonelada é de R\$ 100,32 para aterros de pequeno porte, então para o presente trabalho este valor foi reajustado com base na inflação do período, chegando à magnitude de aproximadamente $R \$ 140,00$ a tonelada. Visando confabular cenários 
otimistas para o projeto foram utilizados os valores de $\mathrm{R} \$ 140,00$ a tonelada para o projeto com administração estritamente pública e R\$ 130,00 para a situação projetada para concessão privada.

No decorrer do fluxo de caixa os cálculos foram ajustados tanto para dez como para quinze anos conforme as estimativas do Índice de Preço ao Consumidor Amplo (IPCA), que é o índice utilizado para o cálculo e projeção sobre a inflação. A taxa depreciação foi calculada linearmente, incidindo apenas sobre o capital fixo. Com relação aos aspectos tributários envolvidos no estudo, foram considerados: o Programa Integração Social (PIS), Contribuição para o Financiamento da Seguridade Social (COFINS), Imposto Sobre Serviço de Qualquer Natureza (ISSQ) Imposto de Renda Pessoa Jurídica (IRPJ) e a Contribuição Social sobre o Lucro Líquido (CSLL). As projeções foram realizadas com o auxílio do software Excel.

\section{Cenário Provável - Administração Pública}

Os custos iniciais para a implantação do projeto baseiam-se na aquisição do terreno, nos instrumentos que compõem o aterro como a geomembrana, geotêxtil o tubo para dreno, tubo para dreno de gás, brita e o poço de monitoramento, licenciamentos ambientais para a liberação do empreendimento, estação de tratamento que podem ser ou não terceirizado, a construção das balanças para pesar a quantidade de lixo que será descartado, plantio de árvores ao redor do aterro, cercamento, construção do setor administrativo e da guarita, os maquinários como caminhão basculante, retroescavadeira e trator com compactador e os custos de consultoria do projeto que representa $5 \%$ sobre o valor do projeto, ou seja, para a consultoria que está elaborando.

Tabela 5: Custos iniciais para a construção do aterro sanitário - cenário provável / administração pública.

\begin{tabular}{ccccc} 
Descrição & Preço Unitário R\$ & Unidade & Quantidade & Total R\$ \\
& & - & 1 & $70.000,00$ \\
Aquisição do Terreno & 70.000 & $\mathrm{~m} 2$ & 13.500 & $216.000,00$ \\
Geomembrana PEAD $2 \mathrm{~mm}$ & 16,00 & $\mathrm{~m} 2$ & 13.500 & $33.750,00$ \\
Geotêxtil - 150 g/m2 & 2,50 & $\mathrm{~m} 2$ & 3000 & $10.500,00$ \\
Tubo para dreno - 0,65 mm & 3,50 & $\mathrm{M}$ & 16 & 960,00 \\
Tubo para drenagem de gás & 60,00 & $\mathrm{~m} 3$ & 100 & $6.200,00$ \\
Brita 5 - gás & 62,00 & $\mathrm{~m} 3$ & 500 & $19.500,00$ \\
Brita 2 - drenagem superficial & 39,00 & - & 4 & $8.800,00$ \\
Poço de monitoramento & $2.200,00$ & - & 1 & $80.000,00$ \\
Sondagens e Licenciamentos & $80.000,00$ & - & 1 & $45.000,00$ \\
Estação de tratamento de efluentes & $45.000,00$ & - & 1 & $85.000,00$ \\
Construção das balanças & 85000 & $\mathrm{muda}$ & 100 & 450,00 \\
Plantio de vegetação ao redor & 4,50 & $\mathrm{M}$ & 500 & $10.000,00$ \\
Cercamento & 20,00 & - & 1 & $50.000,00$ \\
Construção & $50.000,00$ & - & 1 & $235.000,00$ \\
Caminhão basculante & $235.000,00$ & - & 1 & $235.000,00$ \\
Retroescavadeira & $235.000,00$ & - & 1 & $690.000,00$ \\
Trator esteira com compactador & $690.000,00$ & - & 1 & $84.808,00$ \\
Custos do projeto & $84.808,00$ & & & $1.880 .968,00$ \\
\hline Custo total & & &
\end{tabular}

Os custos fixos foram calculados para o primeiro ano do projeto, estes foram estimados em função das variações de mercado, por isso, o fluxo de caixa sofre alterações no decorrer dos anos, pois são ajustados conforme a estimativa da inflação. Para os cálculos da estimativa foi utilizado o software Excel. 
Os custos fixos são compostos por mão de obra que conta com 10 funcionários no qual estão inclusos um operador para a balança, supervisor, serviços gerais, três vigias já embutidos os adicionais noturnos e insalubridade, motorista, dois operadores de máquina e um engenheiro, os valores de salários, são compatíveis com os valores do mercado atual. O contador com um custo mensal de um salário mínimo; energia elétrica; abastecimento de água; a monitoração da água subterrânea (duas por ano) e por fim os custos com telefone e internet.

Tabela 6: Custos fixos, mensal e anual para o primeiro ano do projeto.

\begin{tabular}{ccrr}
\hline Descrição & Quantidade & Custo mensal & \multicolumn{1}{c}{ Custo anual } \\
\hline Mão-de-obra & 10 & $20.358,00$ & $244.296,00$ \\
Contador & 1 & 880,00 & $10.560,00$ \\
Energia Elétrica & - & 500,00 & $6.000,00$ \\
Abastecimento de água & - & 400,00 & $4.800,00$ \\
Monitoramento água subterrânea & 2 /ano & 70,00 & 140,00 \\
Telefone/Internet & - & 100,00 & $1.200,00$ \\
\hline Total & & $22.308,00$ & $266.996,00$ \\
\hline
\end{tabular}

Em relação aos custos variáveis assim como os custos fixos os cálculos foram projetados para o primeiro ano do empreendimento, onde estão inclusos o combustível que será utilizado pelos equipamentos, esses que foram reajustados conforme a previsão do reajuste do preço do óleo diesel dos últimos 10 anos; a manutenção e os gastos inesperados não sofreram alteração em virtude da falta de dados históricos referentes a esse processo mantendo-se os mesmos valores, novamente foi utilizado o software Excel para fazer as projeções. Os índices econômicos para este cenário são apresentados a seguir na Tabela 8.

Tabela 7: Custos variáveis, mensal e anual para o primeiro ano do projeto.

\begin{tabular}{llll}
\hline Descrição & Quantidade & Custo mensal & Custo anual \\
\hline Combustível Maquinário & $4 \mathrm{~h} /$ dia & $1.000,00$ & $12.000,00$ \\
Manutenção & - & $2.000,00$ & $24.000,00$ \\
Gastos inesperados & - & $1.000,00$ & $12.000,00$ \\
\hline Total & & $4.000,00$ & $48.000,00$ \\
\hline
\end{tabular}

Tabela 8: Análise econômica do projeto / cenário provável referente à administração pública.

\begin{tabular}{cc}
\hline Índices & Valores \\
\hline VPL & $-\mathrm{R} \$ 2.381 .946,74$ \\
TIR & não foi possível calcular \\
PAYBACK & - \\
\hline
\end{tabular}

A análise dos resultados não foi satisfatória, o VPL foi negativo em R\$ 2.381.946,74 centavos, considerando que o preço da tonelada é de $\mathrm{R} \$ 58,92$, ou seja, o retorno do projeto foi menor que o investimento inicial tornando-o inviável, o que sugere que este projeto seja reprovado, a TIR não foi possível ser calculada, pois como os valores do fluxo de caixa livre foram negativos, o valor tornou-se pequeno, a tal ponto, que o Excel o considerou como zero, impossibilitando seu cálculo. O PAYBACK, não retornou resultado já que, dentro desse período as receitas líquidas geradas não foram suficientes para pagar o empreendimento.

\section{Cenário Otimista - Administração Pública}


Neste cenário os custos iniciais do projeto sofreram algumas mudanças, uma vez que, não foram considerados os custos de aquisição do terreno, os custos de consultoria do projeto e os equipamentos utilizados para esta análise como caminhão basculante, retroescavadeira e trator com compactador são equipamentos usados, com intuito de diminuir os custos iniciais do projeto, os demais materiais que serão utilizados para o empreendimento não foram alterados. A Taxa Mínima de Atratividade (TMA) ou custo de oportunidade também foi alterada, reduzindo-se de $15 \%$ para $12 \%$, uma diminuição de $20 \%$. O 'Imposto Sobre Serviços de Qualquer Natureza' também não foram considerados. Uma vez que, esse imposto trata-se se uma receita municipal é condizente pensar que, já que o aterro é administrado pela prefeitura neste cenário, que esta pudesse abrir mão dessa receita, pois, estaria pagando a si mesmo.

Tabela 9: Custos iniciais para a construção do aterro sanitário - cenário otimista / administração pública.

\begin{tabular}{crrrr}
\hline Descrição & Preço Unitário R\$ & Unidade & Quantidade & Total R\$ \\
& & & & \\
\hline Aquisição do Terreno & 0,00 & - & 1,00 & 0,00 \\
Geomembrana PEAD $2 \mathrm{~mm}$ & 16,00 & $\mathrm{~m} 2$ & $13.500,00$ & $216.000,00$ \\
Geotêxtil - 150 g/m2 & 2,50 & $\mathrm{~m} 2$ & $13.500,00$ & $33.750,00$ \\
Tubo para dreno - 0,65 mm & 3,50 & $\mathrm{~m} 2$ & $3.000,00$ & $10.500,00$ \\
Tubo para drenagem de gás & 60,00 & $\mathrm{M}$ & 16,00 & 960,00 \\
Brita 5 - gás & 62,00 & $\mathrm{~m} 3$ & 100,00 & $6.200,00$ \\
Brita 2 - drenagem superficial & 39,00 & $\mathrm{~m} 3$ & 500,00 & $19.500,00$ \\
Poço de monitoramento & $2.200,00$ & - & 4,00 & $8.800,00$ \\
Sondagens e Licenciamentos & $80.000,00$ & - & 1,00 & $80.000,00$ \\
Estação de tratamento de efluentes & $45.000,00$ & - & 1,00 & $45.000,00$ \\
Construção das balanças & $85.000,00$ & - & 1,00 & $85.000,00$ \\
Plantio de vegetação ao redor & 4,50 & Muda & 100,00 & 450,00 \\
Cercamento & 20,00 & $\mathrm{M}$ & 500,00 & $10.000,00$ \\
Construção & $50.000,00$ & - & 1,00 & $50.000,00$ \\
Caminhão basculante & $117.500,00$ & - & 1,00 & $117.500,00$ \\
Retroescavadeira & $117.500,00$ & - & 1,00 & $117.500,00$ \\
Trator esteira com compactador & $345.000,00$ & - & 1,00 & $345.000,00$ \\
Custos do projeto & 0,00 & & 1,00 & 0,00 \\
\hline Custo total & & & & $1.146 .160,00$ \\
\hline
\end{tabular}

Em relação aos custos fixos e variáveis mantiveram-se inalterados visto que, se trata da análise do mesmo projeto. Quanto aos índices econômicos para este cenário são apresentados na Tabela 10.

Tabela 10: Análise econômica do projeto / cenário otimista referente à administração pública.

\begin{tabular}{cc}
\hline Índices & Valores \\
\hline VPL & $\mathrm{R} \$ 39.738,08$ \\
TIR & $12,79 \%$ \\
PAYBACK & 9,5 \\
\hline
\end{tabular}

A análise de viabilidade econômica para este cenário foi satisfatória, devido ao valor positivo apresentado no VPL que foi de $\mathrm{R} \$ 39.738,08$ centavos, onde o valor da tonelada de lixo foi reajustada para $\mathrm{R} \$ 140,00$, implica que, o valor obtido no projeto pagará o investimento inicial obtendo uma margem de lucro, ou seja, o projeto, nesse cenário, é viável. A taxa interna de retorno do investimento é de $12,79 \%$ que será comparada com a TMA ou custo de oportunidade, mas, para que a TIR fosse satisfatória a TMA foi reduzida em $20 \%$, essa taxa leva em consideração o rendimento em um investimento de baixo risco, no qual o gestor poderia aplicar o dinheiro ao invés de investir no projeto. No que diz respeito ao PAYBACK, o período de recuperação do investimento foi de nove anos cinco meses e vinte e cinco dias, ou seja, após esse período, 
o projeto tornou-se operacionalmente viável. Observa-se que, o projeto foi viável a partir do momento em que o preço da tonelada aumentou muito o valor, quando comparado com o cenário anterior.

\section{Cenário Provável - Concessão Privada}

Para este cenário provável de concessão privada que é o ato de conceder algo, condizente com a Lei 8.987 de 13 de fevereiro de 1995, Artigo 2º, Inciso Il que a "concessão de serviço público: a delegação de sua prestação, feita pelo poder concedente, mediante licitação, na modalidade de concorrência, à pessoa jurídica ou consórcio de empresas que demonstre capacidade para seu desempenho, por sua conta e risco e por prazo determinado", foi utilizado um período de quinze anos para a realização desta análise. Os custos iniciais do projeto permaneceram os mesmos apresentados na Tabela 5. Quantos aos custos fixos e variáveis também permaneceram inalterados apresentados nas Tabelas 6 e 7, no entanto foi alterado apenas o valor total dos custos ao final dos quinze anos. Os índices da viabilidade econômica deste cenário são apresentados na Tabela 11.

Tabela 11: Analise econômica do projeto / cenário provável referente à concessão privada.

\begin{tabular}{cc}
\hline Índices & Valores \\
\hline VPL & $-\mathrm{R} \$ \mathrm{R} \$ 2.557 .991,84$ \\
TIR & Não foi possível calcular \\
PAYBACK & - \\
\hline
\end{tabular}

Para este cenário foi inserido o imposto do ISSQN na análise, uma vez que estará sob a responsabilidade da administração privada. Os resultados esperados dessa análise não foram alcançados, o VPL apresentou um valor negativo de R\$ 2.557.991,84 centavos, sendo que para este cenário também foi utilizado o preço de $\mathrm{R} \$ 58,92$, valor cobrado pela tonelada. A TIR, não retornou resultado, visto que os fluxos de caixa livre gerados pelo projeto, nesse cenário, foram todos negativos, deixando o valor do índice diminuto ao ponto do Excel considerá-lo como zero. O PAYBACK também não foi calculado em virtude, de nesse período, o projeto não se pagar.

\section{Cenário Otimista - Concessão Privada}

Este cenário apresenta para a concessão privada uma perspectiva otimista, onde os custos iniciais do projeto são os mesmos apresentados na Tabela 9, no qual os custos com aquisição do terreno não foram considerados, supondo que a prefeitura pudesse doar esse terreno em termos de concessão para que o investidor privado pudesse explorar durante o tempo especifico que no caso são 15 anos. Foram retirados os custos de consultoria do projeto em virtude da probabilidade da empresa possuir Know-how, ou seja, ter pessoal qualificado para elaborar tais projetos e os equipamentos utilizados para esta análise como caminhão basculante, retroescavadeira e trator com compactador são equipamentos usados, novamente, com o objetivo de diminuir os custos iniciais do projeto. A TMA considerada também foi de $12 \%$ ao ano. Os demais itens que serão utilizados para o projeto não foram alterados. Os índices da viabilidade econômica são apresentados na Tabela 12. 
Tabela 12: Analise econômica do projeto / cenário otimista referente à concessão privada.

\begin{tabular}{cc}
\hline Índices & Valores \\
\hline VPL & $\mathrm{R} \$ 56.292,75$ \\
TIR & $12,85 \%$ \\
PAYBACK & 12,4 \\
\hline
\end{tabular}

Assim como no cenário otimista anterior, da Administração Pública, também foi desconsiderado o imposto do ISSQN, partindo do pressuposto que a Prefeitura Municipal abra mão dessa receita, em virtude dos benefícios ambientais. Os resultados dessa análise para o cenário de concessão privada foram aceitáveis, já que o VPL demonstrou um resultado positivo de $\mathrm{R} \$ 56.292,75$ centavos, ao preço cobrado pela tonelada de $R \$ 130,00$, a taxa apresentada pela TIR foi de $12,85 \%$ visto que, novamente a TMA sofreu uma redução de $20 \%$ portanto, para este cenário o empreendimento é viável, uma vez que o VPL e a TIR foram maior que zero. O PAYBACK demonstrou que o tempo de recuperação do projeto será de doze anos quatro meses e um dia. Verifica-se que o projeto, assim como no segundo cenário - administração pública é viável, pois o preço da tonelada aumentou consideravelmente.

Dentre os cenários apresentados das análises dos fluxos de caixa para a implantação de um aterro sanitário, o mais atrativo é o quarto cenário - Concessão Privada, considerando que o preço da tonelada do lixo é a menor apresentada entre os cenários viáveis e possui o maior VPL e TIR, mesmo considerando um período maior de retorno do investimento.

\section{CONSIDERAÇÕES FINAIS}

O presente trabalho teve como objetivo realizar a análise econômica e financeira para a implantação de um aterro sanitário no município de Cabaceiras do Paraguaçu (BA). Para esta análise foi realizado uma projeção dos habitantes para os próximos dez e quinze anos do município bem como, o potencial de resíduos sólidos gerados. O capital inicial necessário para a implantação do projeto, assim como os custos fixos e variáveis, e, a elaboração do fluxo de caixa para a realização da análise econômica e financeira do empreendimento também foram estimados. Foram utilizadas as ferramentas de engenharia econômica para o diagnóstico como VPL, a TIR e o PAYBACK.

A partir dos resultados obtidos nota-se que para a implantação de um aterro sanitário de pequeno porte no município é necessária uma área de $10.000 \mathrm{~m}^{2}$ no qual tem a capacidade de receber até 100 toneladas de lixo por dia. Quanto à análise econômica e financeira do projeto foram realizadas projeções para 10 anos (cenários para administração pública) e 15 anos (cenários para concessão privada).

A análise de viabilidade tanto para primeiro cenário (provável) voltado para a administração pública quanto para o terceiro cenário (provável) de concessão privada, demonstram que projeto é inviável, uma vez que, diante dos investimentos iniciais e dos custos fixos e variáveis o projeto apresentou VPL negativo, considerando que o preço da tonelada foi $\mathrm{R} \$ 58,92$ para ambos os cenários e as projeções com um aumento de $3 \%$ ao ano, mesmo assim não foi possível cobrir os custos e despesas do empreendimento para o período de dez anos e quinze anos, a TIR não foi possível ser calculada, e, o PAYBACK não teve resultados visto que, dentro do período proposto o fluxo de caixa não se pagou. 
Já no segundo cenário (otimista) referente à administração pública e no quarto cenário (otimista) de concessão privada o projeto é viável, devido à redução dos custos iniciais como, por exemplo, o custo do terreno, a consultoria do projeto, equipamentos e a carga tributária do ISSQN. Quanto à análise de viabilidade, o preço cobrado pela tonelada de lixo, no segundo cenário foi de $\mathrm{R} \$ 140,00$ e no quarto cenário de $\mathrm{R} \$ 130,00$ para que o VPL fosse positivo, a TMA foi reduzida em 20\% para que no segundo cenário a TIR fosse de $12,79 \%$ e no quarto cenário de $12,85 \%$, visando estimular o investimento.

Portanto para possuir um aterro sanitário no município é preciso escala de resíduos, e, um município de pequeno porte como é o caso de Cabaceiras do Paraguaçu (BA), não possui uma grande quantidade de lixo gerada diariamente, visto que, o aterro só ficou viável quando se aumentou muito o preço da tonelada de lixo recebido.

Apesar da análise não ter sido viável, mesmo para os cenários otimistas foram realizadas várias alterações para que os índices apresentassem valores minimamente satisfatórios, recomenda-se a implantação de um aterro sanitário em termos de concessão à iniciativa privada (quarto cenário), dado os benefícios sociais que este pode proporcionar ao município como ter um local especifico para o descarte dos resíduos sólidos melhorando a saúde ambiental, uma vez que, esse lixo não será jogado a céu aberto ou incinerado, impedir a ação de catadores de lixo, caracterizado como subemprego, possibilitar um tratamento adequado para o chorume evitando a contaminação do solo, das águas superficiais e subterrâneas, além do enquadramento da Lei $12.305 / 2010$, tendo em vista a preservação do meio ambiente.

Como sugestões, a pesquisa preconiza verificar a existência de municípios entorno que não possuam aterros sanitários de acordo com as normas técnicas, prestando serviço de recebimento final dos resíduos sólidos, isso faria com que o volume de lixo aumentasse e consequentemente a receita, auxiliando no processo de viabilidade.

Outra sugestão, conforme a Lei 12.305 de 2010, os aterros devem ser autossustentáveis, ou seja, precisam desenvolver atividades que não necessitem do investimento periódico de capital público em suas operações. Para isso, fazem-se necessários novos estudos sobre a implantação de usinas de reciclagem ou compostagem em associação com cooperativas, no intuito de analisar se há viabilidade para a produção de tais produtos, agregando maior nível de receita, auxiliando também no processo de viabilidade.

\section{REFERÊNCIAS}

ABNT. NBR 10004: Classificação dos resíduos sólidos. São Paulo: ABNT, 2014.

ABRELPE. Panorama dos resíduos sólidos no Brasil. São Paulo: ABRELPE, 2013.

BRASIL. Lei n. 12.305 de 2 de agosto de 2010. Institui a Política Nacional de Resíduos Sólidos. Brasília: DOU, 2010.

BRASIL. Lei 6.938 de 31 de agosto de 1981. Dispõe sobre a Política Nacional do Meio Ambiente. Brasília: DOU, 1981.
BRASIL. Lei 8.987 de 13 de fevereiro de 1995. Dispõe sobre o regime de concessão e permissão da prestação de serviços públicos. Brasília: DOU, 1995.

BRASIL. Decreto Lei 9.782 de 26 de janeiro de 1999. Define o Sistema Nacional de Vigilância Sanitária. Brasília: DOU, 1999.

CONAMA. Resolução no404 de 11 de novembro de 2008. Estabelece critérios e diretrizes para o licenciamento ambiental de aterro sanitário de pequeno porte de resíduos sólidos urbanos. Brasília: DOU, 2008. 
DEMO, P.. Metodologia do conhecimento científico. 3 ed. São Paulo: Atlas, 2000.

FGV. Estudo sobre os aspectos econômicos e financeiros da implantação e operação de aterros sanitários. Rio de Janeiro: FGV, 2007.

GIL, A. C.. Como elaborar projetos de pesquisa. 4 ed. São Paulo: Atlas, 2002

GITMAN, L. J.. Princípios da administração financeira. 10 ed. São Paulo: Pearson Addison Wesley, 2004.

GROPPELLI, A. A.; NIKBAKHT, E.. Administração financeira. 2 ed. São Paulo: Saraiva, 2006.

HIRSCHFELD, H.. Engenharia econômica e análise de custos: aplicações práticas para economistas, engenheiros, analistas de investimentos e administradores. 7 ed. São Paulo: Atlas, 2012.

HOJI, M.. Administração financeira: uma abordagem prática. 5 ed. São Paulo: Atlas, 2004.

HOJI, M.. Administração financeira e orçamentária: matemática financeira aplicada, estratégias financeiras, orçamento empresarial. 6 ed. São Paulo: Atlas, 2007.

IBGE. Censo demográfico 2010. Brasília: IBGE, 2010.

IBGE. Pesquisa Nacional de Saneamento Básico. Brasília: IBGE, 2008.

MONTEIRO, J. H. P.. Manual de gerenciamento integrado de resíduos sólidos. Rio de Janeiro: IBAM, 2001.

MMA. Estudo sobre o potencial de geração de resíduos de saneamento (lixo, esgoto), visando incrementar o biogás como fonte de alternativa de energia renovável. Brasília: MMA, 2010.

MMA. Plano Nacional De Resíduos Sólidos. Brasília: MMA 2012.
MORAIS, J. L.; SIRTORI, C.; PERALTA-ZAMORA, P. G.. Tratamento de chorume de aterro sanitário por fotocatálise heterogênea integrada a processo biológico convencional. Química Nova, v.29, n.1, p.20-23, 2006.

NASCIMENTO, L. C.. Avaliação da política de revitalização da fumicultura no município de Cabeceiras do Paraguaçu no período de 2000 a 2005. Salvador: SEI, 2007.

PERS-BA. A Política Estadual De Resíduos Sólidos (PERS/BA) Lei no 12.932/2014 e a Logística Reversa. Salvador: PMS, 2014.

PNUD. Estudo sobre o Potencial de Geração de Energia a partir de Resíduos de Saneamento (lixo, esgoto), visando incrementar o uso de biogás como fonte alternativa de energia renovável. São Paulo: PNDU, 2010.

ROSS, S. A.. Princípios de administração financeira. 2 ed. São Paulo: Atlas, 2008.

SDU; MMA. Plano de regionalização da Gestão Integrada de Resíduos Sólidos do Estado da Bahia e Elaboração do Plano Regional de Gestão Integrada de Resíduos Sólidos para os Municípios da Bacia do Rio São Francisco. Brasília: SDU/MMA, 2012.

SILVA, H.; BARBIERI, A. F.; MONTE-MÓR, R. L.. Demografia do consumo urbano: um estudo sobre a geração de resíduos sólidos domiciliares no município de Belo Horizonte. Revista Brasileira de Estudos Populacionais, Rio de Janeiro, v.29, n.2, p.421-449, 2012.

SOUSA, R. S. M.; GAIA, D. S.; RANGEL, L. S.. Geração de energia através do lixo. Revista de divulgação do projeto Universidade Petrobrás e IF Fluminense, v.1, p.337-381 2010.

VILHENA, A.. Lixo municipal: manual de gerenciamento integrado. 3 ed. São Paulo: CEMPRE, 2010.

YIN, R. K.. Estudo de caso: planejamento e métodos. 2 ed. Porto Alegre: Bookman, 2001. 